\title{
BMJ Open Outcomes of domestic violence screening at an acute London trust: are there missed opportunities for intervention?
}

\author{
Charlotte Warren-Gash, ${ }^{1,2}$ Angela Bartley, ${ }^{1}$ Jude Bayly, ${ }^{3}$ Peter Dutey-Magni, ${ }^{1,4}$ \\ Sarah Edwards, ${ }^{5}$ Sara Madge, ${ }^{6}$ Charlotte Miller, ${ }^{7}$ Rachel Nicholas, ${ }^{8}$ \\ Sheila Radhakrishnan, ${ }^{7}$ Leena Sathia, ${ }^{5}$ Helen Swarbrick, ${ }^{9}$ Dee Blaikie, ${ }^{10}$ \\ Alison Rodger ${ }^{1,11}$
}

To cite: Warren-Gash $\mathrm{C}$, Bartley A, Bayly J, et al. Outcomes of domestic violence screening at an acute London trust: are there missed opportunities for intervention?. BMJ Open 2016;6:e009069. doi:10.1136/bmjopen-2015009069

- Prepublication history for this paper is available online. To view these files please visit the journal online (http://dx.doi.org/10.1136/ bmjopen-2015-009069).

Received 12 June 2015 Revised 19 November 2015 Accepted 23 November 2015

CrossMark

For numbered affiliations see end of article.

Correspondence to Dr Charlotte Warren-Gash; c.warren-gash@ucl.ac.uk

\section{ABSTRACT}

Objectives: Domestic violence screening is advocated in some healthcare settings. Evidence that it increases referral to support agencies or improves health outcomes is limited. This study aimed to (1) investigate the proportion of hospital patients reporting domestic violence, (2) describe characteristics and previous hospital attendances of affected patients and (3) assess referrals to an in-house domestic violence advisor from Camden Safety Net.

Design: A series of observational studies.

Setting: Three outpatient clinics at the Royal Free London NHS Foundation Trust.

Participants: 10158 patients screened for domestic violence in community gynaecology, genitourinary medicine (GUM) and HIV medicine clinics between 1 October 2013 and 30 June 2014. Also 2253 Camden Safety Net referrals over the same period.

Main outcome measures: (1) Percentage reporting domestic violence by age group gender, ethnicity and clinic. (2) Rates of hospital attendances in the past 3 years for those screening positive and negative. (3) Characteristics, uptake and risk assessment results for hospital in-house domestic violence referrals compared with Camden Safety Net referrals from other sources.

Results: Of the 10158 patients screened, $57.4 \%$ were female with a median age of 30 years. Overall, $7.1 \%$ reported ever-experiencing domestic violence, ranging from $5.7 \%$ in GUM to $29.4 \%$ in HIV services. People screening positive for domestic violence had higher rates of previous emergency department attendances (rate ratio (RR) $1.63,95 \% \mathrm{Cl} 1.09$ to 2.48 ), emergency inpatient admissions (RR 2.27, 95\% Cl 1.37 to 3.84 ) and day-case admissions (RR 2.03, 95\% Cl 1.23 to 3.43 ) than those screening negative. The 77 hospital referrals to the hospital-based domestic violence advisor during the study period were more likely to be taken up and to be classified as high risk than referrals from elsewhere.

Conclusions: Selective screening for domestic violence in high-risk hospital clinic populations has the potential to identify affected patients and promote good uptake of referrals for in-house domestic violence support.

\section{Strengths and limitations of this study}

This study describes a multiagency collaborative approach to domestic violence in a hospital that includes routine screening in three outpatient clinics, staff training and hosting an in-house domestic violence advisor from a local support service.

- Few previous studies have investigated whether implementing domestic violence screening in health settings translates to increased referrals to specialist support services.

- This study shows that implementing domestic violence screening for high-risk hospital clinic populations identifies large numbers of people who have experienced past or current domestic violence. Having a hospital-based independent domestic and sexual violence advisor enhanced the number and uptake of referrals for domestic violence support. Hospital referrals were more likely to be classified as high risk than referrals to the local domestic violence service received from elsewhere.

- Study limitations include missing data on results of some risk assessments, lack of follow-up data on long-term health outcomes and lack of costeffectiveness data. These will be important areas for future evaluation.

\section{INTRODUCTION}

Domestic violence is common in the UK: around $30 \%$ of women and $16 \%$ of men have experienced some form of domestic abuse since the age of 16 years. ${ }^{1}$ It is associated with poor health outcomes including acute injuries as well as chronic physical and mental health conditions. It impacts negatively on children, families and wider society ${ }^{2}$ with high human and economic costs. Women experiencing domestic violence use more emergency department (ED), hospital outpatient, primary care, pharmacy and 
specialty services including mental health services than non-abused women. ${ }^{3}$ Despite this, domestic violence is under-reported in healthcare settings and few victims access domestic violence services. ${ }^{4}$

The National Institute of Health and Care Excellence (NICE) recently published guidance on how health, social care and related organisations should identify, prevent and reduce domestic abuse. ${ }^{5}$ Recommendations included creating an environment for disclosing domestic violence and abuse, ensuring that trained front line staff asked about domestic violence, and having clear pathways for referral to specialist services. NICE recommends routinely asking patients in high-risk settings such as antenatal, sexual health, alcohol and drug services whether they have experienced domestic violence, regardless of presentation-an approach known as 'selective screening'-but acknowledges that there is insufficient evidence to advocate universal screening in all healthcare settings. The WHO adopts a similar position, supporting selective enquiry based on clinical considerations and in settings such as antenatal care, over routine enquiry or universal screening in all healthcare encounters. ${ }^{6}$ Recent systematic reviews suggest that while screening for intimate partner violence in some healthcare settings increases identification of domestic violence, it is unclear whether screening increases referrals to support agencies, reduces violence recurrence or improves long-term health outcomes. ${ }^{78}$

At the Royal Free London NHS Foundation Trust (RFL) we have shown that domestic violence makes a notable contribution to assaults presenting at the $\mathrm{ED},{ }^{9}$ although the impact of domestic violence on patients in other parts of the hospital is less clear. We therefore instigated a programme of domestic violence screening by frontline staff for patients attending three outpatient clinics including sexual health, identified by NICE as a high-risk setting, with onward referral to an in-house support service as appropriate. We aimed to investigate the proportion of screened patients reporting domestic violence, describe characteristics and previous hospital attendance patterns of affected patients and assess outcomes of screening including uptake of referrals to support services to inform design of future interventions.

\section{METHODS}

\section{Domestic violence screening and response}

We designed a simple screening tool and referral pathways to specialist domestic violence support services in collaboration with colleagues from Camden Safety Net $(\mathrm{CSN}),{ }^{10}$ an organisation offering confidential advice and support to people affected by domestic and sexual violence who live, work or study in the London Borough of Camden. We trained frontline staff working in community gynaecology, HIV medicine and genitourinary medicine (GUM) clinics at the RFL to ask all patients about domestic violence and signpost patients to services. Staggered screening was introduced to GUM on 01 October 2013, Community gynaecology on 01 December 2013 and HIV on 15 January 2014. Domestic violence screening was already well established in maternity services before these interventions, so maternity was not included in this evaluation. From October 2013 an independent domestic and sexual violence advisor (IDSVA) from CSN was hosted at the hospital from 09:00 to 17:00 Monday to Friday to see referrals (regardless of borough of residence), and advise, train and support staff on issues around domestic violence. We raised awareness of the service by introducing the IDSVA at staff meetings, distributing cards containing IDSVA contact details and posting domestic violence pages on the hospital intranet site. The work was coordinated through a multidisciplinary domestic violence steering group at the hospital, which reported to the Trust's Safeguarding Board.

\section{Assessment of domestic violence status}

The screening tool comprised an initial standardised question: 'Have you ever been emotionally or physically hurt by your partner, ex-partner or family member?' Asked by multidisciplinary clinic staff to all patients in a private area when the patient was alone, this was used to ascertain whether or not a person had ever experienced domestic violence. For those who responded positively, a standard follow-up question: 'Are you still in contact with this person, or are they still causing you or your family issues?' was used to determine whether domestic violence was current or had happened in the past. For those currently experiencing domestic violence, suggested actions were to determine whether any vulnerable people lived in the household and to refer as appropriate to child or adult safeguarding leads, social services and the IDSVA. Giving a lip salve with a domestic violence helpline number on it was also recommended if the patient declined a referral or was not currently at risk, but might become so in the future.

\section{Overview of evaluation}

We first compared numbers and characteristics of those screening positive and negative for domestic violence at the three RFL clinics, including patterns of previous RFL attendance, to quantify potential missed opportunities for identifying domestic violence. Second, we investigated referrals for domestic violence support by comparing characteristics of affected patients referred to the hospital IDSVA (some identified through screening; some identified through other routes) with CSN referrals from other sources for example, the police and social services.

\section{Data sources}

\section{Screening data}

Data on domestic violence screening were collected by staff in community gynaecology clinics, HIV and GUM clinics at the RFL between 1 October 2013 and 30 June 
2014-a period judged sufficient to embed the IDSVA service within the hospital. Paper-based forms (used in community gynaecology and HIV clinics) included date, location and result of screening as well as a patient's medical record number (MRN). MRNs were then matched with RFL electronic records from commissioning data sets (accident and emergency, admitted patient care, outpatient attendances) to obtain demographic information and hospital attendance history. Numbers and rates of previous attendances at the RFL in the 3 years before screening began that is, from October 2010 were calculated for ED attendances, inpatient stays and outpatient clinic attendances (any specialty) for those screening positive and negative. Only forms with exact matches to MRN were included in analyses. In the GUM clinic, screening data were collected electronically under a patient's unique GUM clinic number. As these numbers cannot be matched to hospital number, the GUM clinic database was interrogated separately to obtain information on demographics and history of GUM attendances only.

\section{Domestic violence service data}

For domestic violence referrals to CSN received between 1 October 2013 and 30 June 2014, an anonymous data set was extracted from the CSN database containing information on month and source of referral, client demographics, whether a referral was taken up, outcomes of any risk assessment and actions taken.

\section{Data analysis}

Descriptive statistics were used to summarise numbers and characteristics of patients screening positive and negative for domestic violence by clinic, age group, gender and ethnicity. The proportion screening positive was expressed as the number who reported everexperiencing domestic violence over the number with a valid screening result. We combined 'current' and 'past' experience as 'any domestic violence' partly due to data recording differences between clinics and because we suspected that some cases reported 'in the past' were actually current. We then compared past hospital attendance rates (presented per 100000 person years of follow-up) between those screening positive and negative separately for ED attendances, inpatient stays and outpatient clinic appointments. We calculated rate ratios (RRs) with their 95\% CIs and $\mathrm{p}$ values from significance tests based on a negative binomial model to accommodate overdispersion. Where there was evidence of differences in results by clinic, we presented results separately by clinic. We used $\chi^{2}$ tests to quantify any differences in demographic characteristics, referral uptake and risk assessment results between people referred to the hospital-based IDSVA and those referred to CSN from other sources.

\section{RESULTS}

\section{Domestic violence screening}

Up to 30 June 2014, 10183 people attending community gynaecology, HIV and GUM clinics at the RFL had a domestic violence screening status recorded. Of these, 25 were excluded due to data recording inconsistencies leaving 10158 screened patients included in analyses. These represented 517 attendees at community gynaecology clinics, 316 at HIV clinics and 9325 at GUM clinics. Of the 10158 screened patients, 5834 $(57.4 \%)$ were female and the median age was 30 years (IQR 25-38).

Across all clinics, 718 (7.1\%) patients screened reported ever-experiencing domestic violence. Figures varied substantially by clinic, ranging from $5.7 \%$ in GUM to $19.0 \%$ in community gynaecology to $29.4 \%$ in HIV (table 1). The proportion ever-experiencing domestic violence increased with age from $5.8 \%$ across all clinics in those aged 16-24 years to $9.2 \%$ in those aged over 65 years. Overall, women were 2.5 times more likely to report domestic violence than men $(9.5 \%$ compared with $3.8 \%$ ).

\section{Previous hospital attendances among screened population ED attendances}

For the 833 patients screened in community gynaecology and HIV, a slightly higher percentage of those screening positive for domestic violence had at least one ED attendance at RFL for any reason in the preceding 3 years than those screening negative: $51(26.7 \%)$ vs 143 (22.3\%), but this difference was not statistically significant $(p=0.24)$. Across both clinics, however, overall rates of previous ED attendances were higher for people screening positive for domestic violence than for those screening negative: RR 1.63 (95\% CI 1.09 to 2.48, $\mathrm{p}=0.019$ ). This was based on $25829 \mathrm{ED}$ attendances per 100000 person years for those reporting domestic violence compared with 15836 attendances per 100000 person years for people with no domestic violence history.

\section{Inpatient spells}

For the same 833 patients, there were more emergency inpatient admissions in the 3 years preceding the start of domestic violence screening for patients screening positive compared with those screening negative: RR 2.27 (95\% CI 1.37 to 3.84 , $\mathrm{p}=0.002$ ). Rates of day-case admissions (usually for elective procedures) were also higher among those screening positive: RR 2.03 (95\% CI 1.23 to $3.43, \mathrm{p}=0.007$ ). In contrast, these patients had slightly lower rates of other elective admissions: RR $0.29(95 \%$ CI 0.09 to $1.07, \mathrm{p}=0.049$ ). Table 2 shows figures by clinic and admission type.

\section{Outpatient attendances}

Patients with HIV who screened positive for domestic violence had slightly higher rates of previous outpatient attendances across various specialties than those who 
Table 1 Number and percentage of patients screening positive for domestic violence (current or previous) by age group, gender, ethnicity and clinic

\begin{tabular}{|c|c|c|c|c|}
\hline Characteristic & $\begin{array}{l}\text { Community gynaecology, } \\
\text { number of persons screening } \\
\text { positive (\% of total screened) }\end{array}$ & $\begin{array}{l}\text { HIV, number of persons } \\
\text { screening positive } \\
\text { (\% of total screened) }\end{array}$ & $\begin{array}{l}\text { GUM, number of } \\
\text { persons screening } \\
\text { positive (\% of total } \\
\text { screened) }\end{array}$ & $\begin{array}{l}\text { Total number } \\
\text { of persons } \\
\text { screened }\end{array}$ \\
\hline \multicolumn{5}{|l|}{ Age group } \\
\hline $0-15$ & $0(0)$ & $0(0)$ & & \\
\hline $16-24$ & $26(21.0)$ & $0(0)$ & $118(5.1)$ & 2445 \\
\hline $25-34$ & $47(21.8)$ & $9(28.1)$ & $222(5.5)$ & 4289 \\
\hline $35-49$ & \multirow{2}{*}{$25(14.1)$} & 57 (35.2) & $137(6.2)$ & \multirow{2}{*}{3424} \\
\hline $50+$ & & 27 (23.1) & $50(6.7)$ & \\
\hline \multicolumn{5}{|l|}{ Gender } \\
\hline Female & 98 (19.0) & $43(40.2)$ & 413 (7.9) & 5834 \\
\hline Male & $\mathrm{N} / \mathrm{A}$ & 50 (23.9) & $114(2.8)$ & 4324 \\
\hline \multicolumn{5}{|l|}{ Ethnicity } \\
\hline White & 55 (19.9) & 49 (31.2) & 347 (5.4) & 6882 \\
\hline Asian & 5 (11.4) & & $32(4.5)$ & \\
\hline Black & 19 (29.2) & $31(27.0)$ & $65(5.6)$ & 2085 \\
\hline Mixed/other & $11(22.4)$ & $8(29.6)$ & $83(8.2)$ & 1191 \\
\hline Unknown & 8 (9.6) & 5 (29.4) & $00(0.2)$ & 1191 \\
\hline Total & $98(19.0)$ & $93(29.4)$ & $527(5.7)$ & 10158 \\
\hline
\end{tabular}

screened negative: RR 1.24 (95\% CI 1.01 to 1.54 ), $\mathrm{p}=0.04$. For community gynaecology patients, however, rates of outpatient department attendances were not significantly different between those screening positive and those screening negative (although numbers were smaller): RR 1.04 (95\% CI 0.62 to 1.88 ) $\mathrm{p}=0.88$ (table 3). GUM patients who screened positive for domestic violence had a higher rate of attendance at the GUM clinic in the preceding 3 years than those screening negative: RR 1.27 (95\% CI 1.09 to 1.49 ), $\mathrm{p}=0.002$.

\section{CSN data}

Over the study period there were 77 referrals to the hospital-based IDSVA, from a range of departments including those not formally participating in domestic violence screening compared with $0 \mathrm{CSN}$ referrals from the hospital in the preceding 8 months. Ages of people referred to the hospital IDSVA ranged from 16 to 79 years (median 29; IQR 25-45) and were not significantly different to the ages of people referred to CSN from other agencies $(p=0.30)$. Almost all hospital IDSVA referrals (94\%) were female compared with $80 \%$ of those referred to CSN from other sources, although two of the departments regularly screening for domestic violence saw exclusively female patients (maternity and gynaecology). People referred to the hospital IDSVA were more likely to access the service than those referred to CSN from other agencies $(\mathrm{p}<0.001)$ (table 4$)$.

Risk assessment results were available for 46 of 77 hospital IDSVA referrals $(59.7 \%)$ compared with 530 of

Table 2 Incidence of inpatient spells by type of admission, screening clinic and screening status from 1 October 2010 to 1 October $2013(n=833)$

\begin{tabular}{|c|c|c|c|c|c|c|c|c|}
\hline \multirow[b]{2}{*}{ Screening clinic } & \multirow[b]{2}{*}{$\begin{array}{l}\text { Type of } \\
\text { admission }\end{array}$} & \multicolumn{3}{|c|}{ Negative screen } & \multicolumn{3}{|c|}{ Positive screen } & \multirow[b]{2}{*}{$\begin{array}{l}\text { Rate ratio } \\
(95 \% \mathrm{Cl})\end{array}$} \\
\hline & & $\begin{array}{l}\text { Total } \\
\text { admissions }\end{array}$ & $\begin{array}{l}\text { Patients } \\
\text { at risk }\end{array}$ & $\begin{array}{l}\text { Admission } \\
\text { rate }^{*}\end{array}$ & $\begin{array}{l}\text { Total } \\
\text { admissions }\end{array}$ & $\begin{array}{l}\text { Patients } \\
\text { at risk }\end{array}$ & $\begin{array}{l}\text { Admission } \\
\text { rate }^{\star}\end{array}$ & \\
\hline Community & Day cases & 54 & 419 & 4296 & 15 & 98 & 5102 & $1.19(0.60$ to 2.25$)$ \\
\hline \multirow[t]{3}{*}{ gynaecology } & $\begin{array}{l}\text { Other } \\
\text { elective }\end{array}$ & 76 & 419 & 6046 & 1 & 98 & 340 & 0.06 (0.00 to 0.99$)$ \\
\hline & Emergency & 54 & 419 & 4296 & 27 & 98 & 9184 & $2.14(1.00$ to 4.76$)$ \\
\hline & Total & 184 & 419 & 14638 & 43 & 98 & 14626 & $1.00(0.54$ to 1.94$)$ \\
\hline \multirow[t]{4}{*}{ HIV } & Day cases & 115 & 221 & 17345 & 87 & 92 & 31522 & 1.81 (0.92 to 3.76$)$ \\
\hline & $\begin{array}{l}\text { Other } \\
\text { elective }\end{array}$ & 28 & 221 & 4223 & 8 & 92 & 2899 & 0.69 (0.21 to 2.32$)$ \\
\hline & Emergency & 69 & 221 & 10407 & 56 & 92 & 20290 & 1.95 (1.00 to 3.87$)$ \\
\hline & Total & 212 & 221 & 31976 & 151 & 92 & 54710 & $1.71(1.02$ to 2.94$)$ \\
\hline
\end{tabular}

Note patients with more than 150 spells were excluded from the analysis.

*Per 100000 person years. 
Table 3 Outpatient attendances by screening clinic and screening status shown for the five most frequent specialties and totals from 1 October 2010 to 1 October $2013(n=833)$

\begin{tabular}{|c|c|c|c|c|c|c|c|c|}
\hline \multirow[b]{2}{*}{$\begin{array}{l}\text { Screening } \\
\text { clinic }\end{array}$} & \multirow[b]{2}{*}{$\begin{array}{l}\text { Outpatient } \\
\text { specialty }\end{array}$} & \multicolumn{3}{|c|}{ Negative screen } & \multicolumn{3}{|c|}{ Positive screen } & \multirow[b]{2}{*}{$\begin{array}{l}\text { Rate ratio } \\
(95 \% \mathrm{Cl}) \\
\end{array}$} \\
\hline & & $\begin{array}{l}\text { Total } \\
\text { admissions }\end{array}$ & $\begin{array}{l}\text { Patients } \\
\text { at risk }\end{array}$ & $\begin{array}{l}\text { Admission } \\
\text { rate }^{\star}\end{array}$ & $\begin{array}{l}\text { Total } \\
\text { admissions }\end{array}$ & $\begin{array}{l}\text { Patients } \\
\text { at risk }\end{array}$ & $\begin{array}{l}\text { Admission } \\
\text { rate }^{\star}\end{array}$ & \\
\hline \multirow{6}{*}{$\begin{array}{l}\text { Community } \\
\text { gynaecology }\end{array}$} & Gynaecology & 585 & 419 & 46539 & 104 & 98 & 35374 & $0.76(0.42$ to 1.44$)$ \\
\hline & $\begin{array}{l}\text { General } \\
\text { medicine }\end{array}$ & 533 & 419 & 42403 & 147 & 98 & 50000 & $1.18(0.51$ to 3.20$)$ \\
\hline & Obstetrics & 152 & 419 & 12092 & 63 & 98 & 21429 & 1.77 (0.44 to 11.72$)$ \\
\hline & $\begin{array}{l}\text { General } \\
\text { surgery }\end{array}$ & 101 & 419 & 8035 & 26 & 98 & 8844 & $1.10(0.38$ to 3.86$)$ \\
\hline & Dermatology & 105 & 419 & 8353 & 1 & 98 & 340 & $0.04(0.00$ to 6.50$)$ \\
\hline & Total† & 2046 & 419 & 162768 & 499 & 98 & 169728 & 1.04 (0.62 to 1.88$)$ \\
\hline \multirow[t]{6}{*}{ HIV } & $\begin{array}{l}\text { Infectious } \\
\text { diseases }\end{array}$ & 4500 & 223 & 672646 & 2088 & 93 & 748387 & $1.11(0.89$ to 1.40$)$ \\
\hline & $\begin{array}{l}\text { General } \\
\text { medicine }\end{array}$ & 619 & 223 & 92526 & 360 & 93 & 129032 & $1.40(0.84$ to 2.40$)$ \\
\hline & $\begin{array}{l}\text { Thoracic } \\
\text { medicine }\end{array}$ & 293 & 223 & 43797 & 247 & 93 & 88530 & 2.02 (0.66 to 7.48$)$ \\
\hline & $\begin{array}{l}\text { General } \\
\text { surgery }\end{array}$ & 187 & 223 & 27952 & 168 & 93 & 60215 & 2.16 (0.66 to 8.86$)$ \\
\hline & Haematology & 152 & 223 & 22720 & 106 & 93 & 37993 & $1.68(0.27$ to 18.00$)$ \\
\hline & Total† & 6808 & 223 & 1017638 & 3533 & 93 & 1266308 & $1.24(1.01$ to 1.54$)$ \\
\hline
\end{tabular}

${ }^{*}$ Per 100000 person years.

†Note totals include outpatient attendances across all specialties, whereas a detailed breakdown is only shown for the top five specialties for each screened population.

2176 people $(24.4 \%)$ referred from other sources. For those who underwent a risk assessment, risk scores were higher in people referred from the hospital than those referred from elsewhere $(\mathrm{p}<0.001)$ (table 5).

Those accessing the hospital IDSVA received a range of interventions including advice and safety planning, onward referral to local support services or specialist services (eg, rape crisis, MARAC-Multi-Agency Risk Assessment Conference) and practical support around obtaining injunctions and criminal prosecutions.

Table 4 Numbers of clients accessing domestic violence support from the hospital compared with those referred from other sources

\begin{tabular}{|c|c|c|}
\hline $\begin{array}{l}\text { Did client access } \\
\text { service? }\end{array}$ & $\begin{array}{l}\text { IDSVA referral } \\
\text { from hospital } \\
(\%)\end{array}$ & $\begin{array}{l}\text { CSN referral from } \\
\text { other source (\%) }\end{array}$ \\
\hline Yes-in person & $38(49.4)$ & $154(7.1)$ \\
\hline $\begin{array}{l}\text { Yes-telephone } \\
\text { contact }\end{array}$ & $17(22.1)$ & $567(26.1)$ \\
\hline $\begin{array}{l}\text { Contact made but } \\
\text { declined further } \\
\text { support }\end{array}$ & $13(16.9)$ & $386(17.7)$ \\
\hline $\begin{array}{l}\text { No-unable to } \\
\text { contact }\end{array}$ & $4(5.2)$ & 361 (16.6) \\
\hline No-out of area & $0(0)$ & $15(0.7)$ \\
\hline No-other reason & $5(6.5)$ & 693 (31.9) \\
\hline Total & 77 & 2176 \\
\hline
\end{tabular}

\section{DISCUSSION}

Through this work we show that implementing selective domestic violence screening by frontline hospital clinic staff for high-risk groups successfully identifies people who have experienced past or current domestic violence. Although only $7.1 \%$ of patients reported experiencing domestic violence overall, figures differed by setting, reaching $29.4 \%$ among patients attending HIV medicine clinics, where $23.9 \%$ of men and $40.2 \%$ of women reported ever-experiencing domestic violence. People reporting domestic violence had presented more frequently to the same hospital in previous years suggesting that there are multiple opportunities for intervention, in particular in the ED or during emergency inpatient stays. There was also good uptake of referrals to an in-house domestic violence service where patients received a range of safety interventions.

Table 5 Outcomes of risk assessment for people accessing domestic violence support from the hospital compared with those referred from other sources

\begin{tabular}{llc}
\hline $\begin{array}{l}\text { Outcome of risk } \\
\text { assessment }\end{array}$ & $\begin{array}{l}\text { IDSVA referral } \\
\text { from hospital } \\
\text { (\%) }\end{array}$ & $\begin{array}{l}\text { CSN referral from } \\
\text { other source (\%) }\end{array}$ \\
\hline High & $13(28.3)$ & $75(14.2)$ \\
Medium & $24(52.2)$ & $133(25.1)$ \\
Standard & $9(19.6)$ & $322(60.8)$ \\
Total & 46 & 530 \\
\hline \multicolumn{2}{l}{ CSN, Camden Safety Net; IDSVA, independent domestic and } \\
sexual violence advisor.
\end{tabular}


Although levels of domestic violence captured in this study are lower overall than those reported in the British Crime Survey, in which around 23\% of people report any history of domestic violence, ${ }^{1}$ hospital patients may be reluctant to disclose a history of domestic violence to healthcare providers due to fears about stigma or safety. ${ }^{11}$ Previous research has shown that interview obtains fewer disclosures of domestic violence than self-administered questionnaires, ${ }^{12}$ but our aim was to equip staff to integrate questions about domestic violence into a standard clinic consultation. We also screened using a standard wording that may not capture all forms of controlling behaviour that constitute domestic violence. Nonetheless in HIV medicine we identify a high proportion reporting domestic violence, which lends support for the model of routine enquiry in high-risk groups. Our study shows that, similar to national figures, women are more likely to experience domestic violence than men. ${ }^{1}$ In our study people subject to domestic abuse had more contact with health services than their non-abused peers, albeit for a range of reasons that may not be domestic violence related, which is in line with previous reports. ${ }^{13}$ Other research suggests that as the severity of violence and control increases, formal services including health and the police become increasingly important in managing the response to domestic violence. ${ }^{14}$

There has previously been a lack of evidence that domestic violence screening in primary care or EDs increases referral to support agencies. ${ }^{15-17}$ We show that having an in-house hospital screening service results in high numbers of referrals to the hospital-based IDSVA, and that people referred from the hospital are more likely to take up the referral than people referred to domestic violence services from elsewhere. We also provide some evidence that more women experiencing domestic violence took up IDSVA referrals than men. We recognise that hospital referrals are not directly comparable to all other referrals $(80 \%$ of whom are from the police): people referred from hospital have had a careful discussion about the merits of onward referral with a healthcare professional; in contrast many police referrals are triggered automatically for example, by calls for domestic disturbances at residential properties which may not be the result of domestic violence. Nonetheless our intervention was successful in enabling some patients experiencing domestic violence to seek help. Our referrals also tended to be higher risk than referrals from elsewhere, although numbers were small. This might partly be explained by the higher volume of inappropriate referrals from non-hospital sources but could also suggest that patients attending a hospital experience a greater degree of domestic violence which is negatively impacting on health and/or are more willing to take action.

There are some limitations to this study. We used routinely collected data from electronic hospital records and the CSN database. As data were not originally collected for research, some fields were incomplete for example, results of risk assessments, and useful extra information for example, on pregnancies, children or types of abuse were not available. In addition, GUM clinic data did not link to the main RFL hospital records so we were unable to review rates of previous hospital attendances for GUM patients in any other departments. Finally, due to difficulties extracting data from hospital systems we do not present a proportion of all attendees screened. Although we demonstrated that domestic violence screening increases uptake to a domestic violence service, we do not have follow-up data on long-term health outcomes, nor did we collect information on potential harms of screening. Nonetheless, several referrals to the hospital-based IDSVA have resulted in successful injunctions against perpetrators as well as criminal prosecutions, but the need to maintain confidentiality precludes further description of these cases. In future it would be useful to consider methods of measuring the effectiveness of referral beyond uptake rates.

We noted several challenges associated with implementing domestic violence screening in hospital, many of which are also highlighted in WHO guidance. ${ }^{6}$ Staff undertaking domestic violence screening need regular training about asking and responding appropriately, private space is necessary for people to be asked safely without risk that the abusive partner is present and clear integrated referral pathways to support services are essential. Some practical challenges were identified, for example, clinics in which it was difficult to get patients on their own, and competing demands on staff time. Using paper screening forms was less effective than electronic forms, as evidenced by the larger numbers screened in GUM where screening was electronically prompted and recorded. In future it would be valuable to compare routine domestic violence screening with case finding based on 'red flag' clinical signs, which may streamline the process in settings such as the ED. Although having a hospital-based IDSVA greatly increased numbers of hospital patients accessing help, there was no IDSVA cover at evenings or weekends, when most domestic violence incidents occur. Lack of long-term funding for the IDSVA service also presented a challenge to embedding the service successfully within the hospital. Finally, we have not assessed the cost-effectiveness of screening for domestic violence for preventing adverse health outcomes but this will be an important aspect of future evaluations.

\section{Conclusion}

Selective screening for domestic violence in high-risk clinical populations has the potential to identify affected patients and enhance uptake of domestic violence services where clear pathways are in place to facilitate referral. 
Author affiliations

${ }^{1}$ Public Health Department, Royal Free London NHS Foundation Trust, London, UK

${ }^{2}$ Institute of Health Informatics, University College London, London, UK ${ }^{3}$ Maternity Department, Royal Free London NHS Foundation Trust, London, UK

${ }^{4}$ Geography \& Environment-Department of Social Statistics \& Demography, University of Southampton, Southampton, UK

${ }^{5}$ Marlborough Clinic, Royal Free London NHS Foundation Trust, London, UK

${ }^{6}$ Ian Charleson Day Centre, Royal Free London NHS Foundation Trust, London, UK

${ }^{7}$ Community Gynaecology, Royal Free London NHS Foundation Trust, London, UK

${ }^{8}$ Community Safety, London Borough of Camden, London, UK

${ }^{9}$ Child Safeguarding, Royal Free London NHS Foundation Trust, London, UK

${ }^{10}$ Adult Safeguarding, Royal Free London NHS Foundation Trust, London, UK

${ }^{11}$ Research Department of Infection \& Population Health, University College London, London, UK

Acknowledgements The authors thank all clinic staff who agreed to take part in domestic violence screening at the Royal Free London NHS Foundation Trust. They acknowledge Reanna Watts and Camden Safety Net for working in partnership with the Royal Free London on a range of issues around domestic violence. CW-G is supported by an NIHR Clinical Lecturer post.

Contributors $C W-G, A B$ and $A R$ contributed to the study concept and design. CW-G, AB, JB, SE, SM, CM, RN, SR, LS, HS, DB and AR contributed to the planning and implementation of domestic violence screening. CWG helped to set up data collection systems. RN and PD-M extracted data. PD-M and CW-G analysed the data. CW-G wrote the first draft of the manuscript. All authors critically revised the manuscript and approved the final version.

Funding This research received no specific grant from any funding agency in the public, commercial or not-for-profit sectors.

Competing interests None declared.

Ethics approval This study was approved by the proportionate review sub-committee of the NRES Committee West Midlands-The Black Country (14/WM/0181).

Provenance and peer review Not commissioned; externally peer reviewed.

Data sharing statement No additional data are available.

Open Access This is an Open Access article distributed in accordance with the Creative Commons Attribution Non Commercial (CC BY-NC 4.0) license, which permits others to distribute, remix, adapt, build upon this work noncommercially, and license their derivative works on different terms, provided the original work is properly cited and the use is non-commercial. See: http:// creativecommons.org/licenses/by-nc/4.0/

\section{REFERENCES}

1. Office for National Statistics. British Crime Survey 2012/2013. Chapter 4-intimate personal violence and partner abuse. http:// www.ons.gov.uk/ons/rel/crime-stats/crime-statistics/focus-on-violentcrime-and-sexual-offences--2012-13/rpt---chapter-4---intimatepersonal-violence-and-partner-abuse.html?format=hi-vis (accessed 18 May 2015).

2. Haegerich TM, Dahlberg LL. Violence as a public health risk. Am J Lifestyle Med 2011:5:392-406.

3. Bonomi AE, Anderson ML, Rivara FP, et al. Health care utilization and costs associated with physical and nonphysical-only intimate partner violence. Health Serv Res 2009;44:1052-67.

4. NHS Barking and Dagenham. Domestic Violence London: a resource for health professionals. http://www.domesticviolence Iondon.nhs.uk/ (accessed 16 Feb 2015).

5. National Institute for Health and Care Excellence. Domestic violence and abuse: how health services, social care and the organisations they work with can respond effectively. February 2014; Report No: 50.

6. World Health Organization. Responding to intimate partner violence and sexual violence against women. WHO clinical and policy guidelines. Geneva, Switzerland, 2013.

7. O'Doherty LJ, Taft A, Hegarty K, et al. Screening women for intimate partner violence in healthcare settings: abridged Cochrane systematic review and meta-analysis. BMJ 2014;348:g2913.

8. O'Doherty L, Hegarty K, Ramsay J, et al. Screening women for intimate partner violence in healthcare settings. Cochrane Database Syst Rev 2015;7:CD007007.

9. Ramsay SE, Bartley A, Rodger AJ. Determinants of assault-related violence in the community: potential for public health interventions in hospitals. Emerg Med J 2014;31:986-9.

10. Camden Safety Net website. https://camden.gov.uk/ccm/content/ policing-and-public-safety/domestic-violence/camden-safety-net.en? source=mega-menu (accessed 18 May 2015).

11. García-Moreno C, Hegarty K, Lucas d'Oliveira AF, et al. The healthsystems response to violence against women. Lancet 2015;385:1567-79.

12. Kataoka $\mathrm{Y}$, Yaju $\mathrm{Y}$, Eto $\mathrm{H}$, et al. Self-administered questionnaire versus interview as a screening method for intimate partner violence in the prenatal setting in Japan: a randomised controlled trial. BMC Pregnancy Childbirth 2010;10:84.

13. Department of Health. Responding to domestic abuse: a handbook for health professionals. London, UK, 2005; Report No: Gateway Ref: 5802.

14. Ansara DL, Hindin MJ. Formal and informal help-seeking associated with women's and men's experiences of intimate partner violence in Canada. Soc Sci Med 2010;70:1011-18.

15. Trautman DE, McCarthy ML, Miller N, et al. Intimate partner violence and emergency department screening: computerized screening versus usual care. Ann Emerg Med 2007;49:526-34.

16. Klevens J, Sadowski L, Kee R, et al. Comparison of screening and referral strategies for exposure to partner violence. Womens Health Issues 2012;22:e45-52.

17. Ahmad F, Hogg-Johnson S, Stewart DE, et al. Computer-assisted screening for intimate partner violence and control: a randomized trial. Ann Intern Med 2009;151:93-102. 